\title{
STUDI PENGARUH SETTING RELE PENGAMAN UNTUK MEMINIMALKAN GANGGUAN SYMPATHETIC TRIP PADA PENYULANG BUNISARI - SUWUNG
}

\author{
I Komang Anom Astana Ady ${ }^{1,}$ I Gede Dyana Arjana ${ }^{2}$, Cok Gede Indra Partha ${ }^{3}$
}

\begin{abstract}
Sympathetic Trip that happened in the electricity distribution system cause the healthy feeder distrupted because feel a disorder in feeder which affected by a disorder.A residual current that flows as a result of disruption of the one phase to ground on the Bunisari feeder as much as 183,9 $A$ will be perceived by the same phase in the Suwung feeder which has a residual current of 196,9 A, that resulting in the accumulation of capacitive current as much as 380,8 A.The efforts obtained to prevent the Sympathetic trip back with ground fault relay setting as Iset $=25,72 \mathrm{~A}$, tms $=$ 0,11 SI with relay working time for 0,27 seconds and for Suwung feeder is obtained Iset $=24,59 \mathrm{~A}$, tms $=0,115 \mathrm{SI}$ with relay working time for 0,286 seconds.
\end{abstract}

Keywords- Protection system, setting ground fault relay, Sympathetic Trip.

Intisari- Sympathetic Trip yang terjadi pada sistem distribusi tenaga listrik menyebabkan penyulang yang sehat ikut terganggu karena merasakan gangguan pada penyulang yang terkena gangguan. Arus sisa yang mengalir akibat gangguan satu fasa ke tanah pada penyulang Bunisari sebesar 183,9 A akan dirasakan oleh fasa yang sama pada penyulang Suwung yang memiliki arus sisa sebesar 196,9 A, sehingga terjadi akumulasi arus kapasitif sebesar 380,8 A. Upaya yang diperoleh untuk menghindari terjadinya Sympathetic Trip kembali dengan setting ground fault relay untuk penyulang Bunisari yaitu Iset = $25,72 \mathrm{~A}, \mathrm{tms}=0,11 \mathrm{SI}$ dengan waktu kerja rele selama 0,27 detik dan untuk penyulang Suwung yaitu diperoleh Iset $=\mathbf{2 4 , 5 9} \mathrm{A}$, tms $=0,115 \mathrm{SI}$ dengan waktu kerja rele selama 0,286 detik.

Kata Kunci-Sistem proteksi, setting ground fault relay, Simpatitik Trip.

\section{PENDAhUluan}

Kebutuhan masyarakat akan energi listrik setiap tahunnya selalu meningkat baik pada rumah tangga maupun pada bidang industrial, hal tersebut akan membawa konsekuensi pada penyediaan tenaga listrik yang lebih besar dengan kualitas tenaga listrik dalam kondisi yang selalu optimal. Pada kondisi ini PT. PLN (Persero) dituntut untuk mampu

\footnotetext{
${ }^{1}$ Mahasiswa, Teknik Elektro dan Komputer Universitas Udayana, Kampus Bukit Jimbaran, Badung, Bali. 80361, Tel. 085338582196 ; e-mail: anom_astana@yahoo.co.id

2, ${ }^{3}$ Dosen Teknik Elektro dan Komputer Universitas Udayana, Kampus Bukit Jimbaran, Badung Bali. 80361, Tel. 0361703315 fax: 0361703315 .
}

I Komang Anom Astana Ady: studi pengaruh setting rele .......... menyediakan pasokan energi listrik yang mempunyai sistem keandalan yang baik maka penyaluran daya listrik ke konsumen harus ditingkatkan secara kontinyu.

Gangguan sistem tenaga listrik adalah setiap keadaan sistem yang menyimpang dari kondisi normal. Gangguan dapat bersifat sementara atau permanen sesuai dengan kerusakan yang ditimbulkan oleh gangguan. Gangguan sementara adalah gangguan yang tidak memerlukan perbaikan untuk beroperasinya sistem secara normal. Sedangkan gangguan permanen adalah gangguan yang mengakibatkan operasi sistem tidak akan cepat beroperasi normal kembali sebelum gangguan diperbaiki.

Walaupun sudah dilengkapi dengan alat proteksi, gangguan bisa saja terjadi salah satunya sympathetic trip. Sympathetic trip adalah suatu gangguan yang sering terjadi pada sebuah penyulang, dimana pemutus tenaga dari penyulang-penyulang yang sehat ikut menjadi trip " $O F F$ ", akibat dari penyulang lain yang sedang mengalami gangguan hubungan pendek satu fasa ke tanah. Pada keadaan normal, bila terjadi gangguan hubungan pendek pada sebuah penyulang, seharusnya rele penyulang itu sendiri yang bekerja mengamankan kejadian, dan tidak mempengaruhi rele penyulang lain. Tetapi dengan kasus sympathetic trip ini, rele proteksi penyulang-penyulang lain (sehat) ikut bekerja, padahal penyulang itu sendiri tidak mengalami gangguan. Sympathetic trip ini terjadi karena adanya gangguan hubungan pendek satu fasa ke tanah, dimana saat kejadian tersebut, arus kapasitif dari penyulang yang tidak terganggu (penyulang sehat) mengalir menuju ke titik gangguan dan melalui rele tanah penyulang sehat.

Untuk menanggulangi masalah sympathetic trip ini maka dapat diatasi dengan menggunakan rele arus lebih dengan karakteristik inverse time sebagai pengganti rele definite time, hal ini dikarenakan karakteristik rele inverse time yang waktu kerjanya bekerja berdasarkan arus gangguan, berbeda dengan definite time yang bekerja tidak berdasarkan arus gangguan karena waktu tundanya tetap. Bila setting rele tanah pada penyulang sehat lebih kecil dari besar arus kapasitif yang mengalir, maka rele tanah ini akan bekerja dan mengirim sinyal ke pemutus tenaga untuk trip. Sedangkan bila setting rele tanah penyulang ini lebih besar dari arus kapasitif yang mengalir, maka rele tanah tidak akan bekerja (penyulang sehat tidak ikut padam). Dengan sistem proteksi yang handal, selektif dan cepat bisa mengurangi daerah pemadaman.

Dalam penelitian ini yang akan dianalisa tentang setting ground fault relay pada sistem distribusi $20 \mathrm{kV}$ dalam upaya 
menanggulangi gangguan sympathetic trip pada penyulang Bunisari - Suwung, dimana diketahui setting ground fault relay yang terpasang pada penyulang Bunisari - Suwung tidak mampu memproteksi gangguan 1 fasa ke tanah sehingga terjadi sympathetic trip pada penyulang tersebut.

\section{TINJAUAN PUSTAKA}

Gangguan satu fasa ke tanah sangat tergantung dari jenis pentanahan dan sistemnya. Gangguan satu fasa ke tanah umumnya bukan merupakan hubung singkat melalui tahanan gangguan, sehingga arus gangguannya menjadi semakin kecil dan tidak bisa terdeteksi oleh Over Current Relay (OCR). Dengan demikian diperlukan rele pengaman gangguan tanah.

Pada gambar di bawah merupakan rangkaian pengawatan dari rele GFR. Rele hubung tanah yang lebih dikenal dengan GFR (Ground Fault Relay) pada dasarnya mempunyai prinsip kerja sama dengan rele arus lebih (OCR) namun memiliki perbedaan dalam kegunaannya. Bila rele OCR mendeteksi adanya hubungan singkat antara fasa, maka GFR mendeteksi adanya hubung singkat ke tanah.

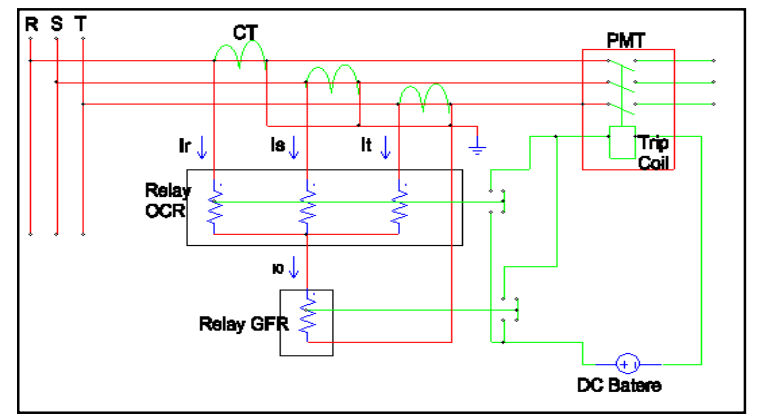

Gambar 1: Rangkaian Pengawatan Rele GFR

\section{A. Setting GFR}

Dalam Ground Fault Relay ada beberapa hal yang harus di-setting, dimana itu arus dan setelan waktunya. Penjelasannya sebagai berikut:

1) Arus Setting GFR

Penyetelan rele GFR pada sisi primer dan sisi sekunder transformator tenaga terlebih dahulu harus dihitung arus setting. Arus setting untuk rele GFR baik pada sisi primer maupun pada sisi sekunder transformator tenaga adalah:

Iset $=0,1 \times$ Arus gangguan tanah terkecil $\mathrm{A}$

\section{2) Setelan Waktu (TMS)}

Hasil perhitungan arus gangguan hubung singkat, selanjutnya digunakan untuk menentukan nilai setelan waktu kerja rele (TMS). Rele GFR menggunakan rumus penyetingan TMS dimana waktu kerja rele yang diinginkann lebih sensitif dari pada rele OCR.

$$
\operatorname{tms}=\frac{\operatorname{tset}\left(\left(\frac{\text { Ifault }}{\text { Iset }}\right)^{0,02}-1\right)}{0,14} \mathrm{SI}
$$

Untuk menentukan nilai TMS yang akan disetkan pada rele GFR sisi incoming $20 \mathrm{kV}$ dan sisi $150 \mathrm{kV}$ transformator tenaga diambil arus hubung singkat 1 fasa ke tanah.
Persamaan untuk menentukan nilai TMS yang akan disetkan pada rele GFR sisi penyulang yang mengalami gangguan Sympathetic Trip menggunakan rumus dibawah ini.

$$
\operatorname{tms}=\frac{\operatorname{tset}\left(\left(\frac{\sqrt{\text { Ifault }^{2}+\text { Ice }^{2}}}{\text { Iset }}\right)^{0,02}-1\right)}{0,14} \mathrm{SI}
$$

B. Pemeriksaan Selektifitas Kerja Ground Fault Relay (GFR) Hasil perhitungan setelan Ground Fault Relay (GFR) masih harus diperiksa. Waktu kerja Ground Fault Relay (GFR) yang terpasang di penyulang dan yang terpasang di incoming trafo tenaga $20 \mathrm{kV}$ sudah bekerja selektif, tetapi masih harus diperiksa apakah memberikan beda waktu kerja (grading time) yang terlalu lama. Untuk gradding time yang terlalu lama, bila terjadi kegagalan kerja Ground Fault Relay (GFR) di penyulang, maka Ground Fault Relay (GFR) di incoming 20 $\mathrm{kV}$ dalam hal ini bekerja sebagai pengaman cadangan menjadi terlalu lama mengetripkan PMTnya sehingga bisa merusak trafo.

Pemeriksaan ini dilakukan terutama pada Ground Fault Relay (GFR) jenis standar inverse, karena setelan waktu TMS pada Ground Fault Relay (GFR) jenis inverse bukan menunjukkan lamanya waktu kerja rele tersebut. Lamanya waktu kerja rele ini ditentukan oleh besarnya arus gangguan yang mengalir direle. Makin besar arus gangguan yang mengalir di rele, makin cepat kerja rele tersebut menutup kontaknya yang kemudian mentripkan PMT.

$$
\mathrm{t}=\frac{0,14 \times T m s}{\left(\frac{\text { Ifault }}{\text { Iset }}\right)^{0,02}-1} \text { detik }
$$

Persamaan yang digunakan dalam mencari waktu kerja rele pada penyulang yang terkena gangguan penyulang lain adalah sebagai berikut.

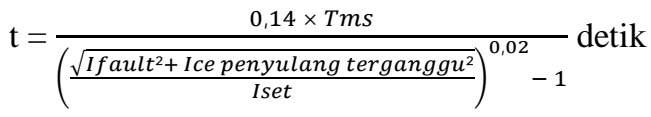

Persamaan yang digunakan dalam mencari waktu kerja rele akibat pertambahan arus kapasitif dari penyulang lain adalah sebagai berikut.

$$
\mathrm{t}=\frac{0,14 \times \text { Tms }}{\left(\frac{\text { Ice peyulang ke } 1+\text { Ice penyulang ke } 2}{\text { Iset }}\right)^{0,02}-1} \text { detik }
$$

\section{Metodelogi}

Penelitian dilakukan di PT. PLN (Persero) Area Jaringan Bali Selatan yang dimulai dari bulan Oktober 2014 sampai dengan Maret 2015. Data-data dalam pembahasan penelitian ini bersumber dari data PT. PLN (Persero) Distribusi Bali Area Jaringan Bali Selatan. Adapun alur analisis pada penelitian ini adalah :

1. Input Data

a. Diagram segaris Bunisari - Suwung

b. Data gangguan sympathetic trip

c. Data penghantar penyulang Bunisari - Suwung

d. Data gardu distribusi penyulang Bunisari - Suwung

2. Menghitung impedansi sumber dan trafo

3. Menghitung impedansi penyulang 
4. Menghitung Isc 1 fasa ke tanah penyulang

5. Menghitung $\mathrm{I}_{\mathrm{C}}$ pada penyulang

6. Setting ground fault rele menggunakan standar invers

7. Pemeriksaan waktu kerja relay penyulan bunisari suwung

\section{Hasil Dan PEMBAhasan}

\section{Arus Hubung Singkat 1 Fasa-Tanah Penyulang Bunisari}

Tabel I : Arus Hubung Singkat 1 Fasa - Tanah Penyulang Bunisari

\begin{tabular}{|l|l|}
\hline $\begin{array}{l}\text { Panjang penyulang } \\
(\%)\end{array}$ & Arus gangguan hubung singkat 1 fasa ke tanah \\
\hline $0 \%$ & $\left(\frac{34641,02}{(2 \times(0+\mathrm{j} 0,98)+(120+\mathrm{j} 8,5)}\right)=283,3 \mathrm{~A}$ \\
\hline $25 \%$ & $\left(\frac{34641,02}{(2 \times(0,51+\mathrm{j} 1,74)+(120,85+\mathrm{j} 12,2)}\right)=276,9 \mathrm{~A}$ \\
\hline $50 \%$ & $\left(\frac{34641,02}{(2 \times(1,01+\mathrm{j} 1,99)+(121,7+\mathrm{j} 15,9)}\right)=272,3 \mathrm{~A}$ \\
\hline $75 \%$ & $\left(\frac{34641,02}{(2 \times(1,52+\mathrm{j} 3,3)+(122,55+\mathrm{j} 19,6)}\right)=263,7 \mathrm{~A}$ \\
\hline $100 \%$ & $\left(\frac{34641,02}{(2 \times(2,03+\mathrm{j} 4,03)+(123,4+\mathrm{j} 23,4)}\right)=257,3 \mathrm{~A}$ \\
\hline
\end{tabular}

D. Arus Hubung Singkat 1 Fasa - Tanah Penyulang Suwung

Tabel 2 : Arus Hubung Singkat 1 Fasa - Tanah Penyulang Suwung

\begin{tabular}{|c|c|}
\hline $\begin{array}{l}\text { Panjang penyulang } \\
(\%)\end{array}$ & Arus gangguan hubung singkat 1 fasa ke tanah \\
\hline $0 \%$ & $\left(\frac{34641,02}{(2 \times(0+j 098)+(120+j 8,5)}\right)=283,3 \mathrm{~A}$ \\
\hline $25 \%$ & $\left(\frac{34641,02}{(2 \times(0,19+j 1,26)+(120,33+j 9,82)}\right)=260,4 \mathrm{~A}$ \\
\hline $50 \%$ & $\left(\frac{34641,02}{(2 \times(0,38+\mathrm{j} 1,54)+(120,66+\mathrm{j} 11,15)}\right)=255,4 \mathrm{~A}$ \\
\hline $75 \%$ & $\left(\frac{34641,02}{(2 \times(0,58+j 1,83)+(120,99+j 12,4)}\right)=250,6 \mathrm{~A}$ \\
\hline $100 \%$ & $\left(\frac{34641,02}{(2 \times(0,77+\mathrm{j} 2,11)+(121,32+\mathrm{j} 13,8)}\right)=245,9 \mathrm{~A}$ \\
\hline
\end{tabular}

\section{E. Perhitungan Arus Kapasitif}

1. Untuk Penyulang Bunisari

$\mathrm{XC}$ (reaktansi kapasitif) AAAC $150 \mathrm{~mm}^{2}$

$$
\begin{aligned}
\mathrm{XC} & =\frac{1}{\left(2 \times \pi \times 50 \times C e \times \text { total panjang saluran } \times 10^{-6}\right)} \\
& =\frac{1}{\left(2 \times \pi \times 50 \times 0,04 \times 650 \times 10^{-6}\right)} \\
& =122,5 \Omega
\end{aligned}
$$

XC (reaktansi kapasitif) AAACS $150 \mathrm{~mm}^{2}$

$$
\begin{aligned}
\mathrm{XC} & =\frac{1}{\left(2 \times \pi \times 50 \times \text { Ce } \times \text { total panjang saluran } \times 10^{-6}\right)} \\
& =\frac{1}{\left(2 \times \pi \times 50 \times 0,06 \times 4337 \times 10^{-6}\right)} \\
& =12,2 \Omega
\end{aligned}
$$

XC (reaktansi kapasitif) XLPE $240 \mathrm{~mm}^{2}$

$$
\begin{aligned}
\mathrm{XC} & =\frac{1}{\left(2 \times \pi \times 50 \times \text { Ce } \times \text { total panjang saluran } \times 10^{-6}\right)} \\
& =\frac{1}{\left(2 \times \pi \times 50 \times 0,263 \times 240 \times 10^{-6}\right)} \\
& =50,4 \Omega
\end{aligned}
$$

$$
\begin{aligned}
& \text { XC (reaktansi kapasitif) MV-TIC } 150 \mathrm{~mm}^{2} \\
& \begin{aligned}
\mathrm{XC} & =\frac{1}{\left(2 \times \pi \times 50 \times C e \times \text { total panjang saluran } \times 10^{-6}\right)} \\
& =\frac{1}{\left(2 \times \pi \times 50 \times 0,236 \times 4182 \times 10^{-6}\right)} \\
& =3,2 \Omega
\end{aligned}
\end{aligned}
$$

I Komang Anom Astana Ady: studi pengaruh setting rele
$\mathrm{XC}$ (reaktansi kapasitif) total $=122,5+12,2+50,4+3,2$

$$
=188,4 \Omega
$$

Maka arus kapasitif Bunisari didapat,

$$
\begin{aligned}
\mathrm{I}_{\mathrm{ce}} & =\left(\frac{3 \times \text { Vsekunder } \times 1000 / \sqrt{3}}{\text { XC total penghantar }}\right) \\
\mathrm{I}_{\mathrm{ce}} & =\left(\frac{3 \times 20 \times 1000 / \sqrt{3}}{188,4}\right) \\
\mathrm{I}_{\mathrm{ce}} & =183,9 \mathrm{~A}
\end{aligned}
$$

2. Untuk Penyulang Suwung

$$
\begin{aligned}
& \mathrm{XC} \text { (reaktansi kapasitif) AAAC } 150 \mathrm{~mm}^{2} \\
& \begin{aligned}
\mathrm{XC} & =\frac{1}{\left(2 \times \pi \times 50 \times \text { Ce } \times \text { total panjang saluran } \times 10^{-6}\right)} \\
& =\frac{1}{\left(2 \times \pi \times 50 \times 0,04 \times 609 \times 10^{-6}\right)} \\
& =130,7 \Omega
\end{aligned}
\end{aligned}
$$

XC (reaktansi kapasitif) AAACS $150 \mathrm{~mm}^{2}$

$$
\begin{aligned}
\mathrm{XC} & =\frac{1}{\left(2 \times \pi \times 50 \times C e \times \text { total panjang saluran } \times 10^{-6}\right)} \\
& =\frac{1}{\left(2 \times \pi \times 50 \times 0,06 \times 2670 \times 10^{-6}\right)} \\
& =19,9 \Omega
\end{aligned}
$$

XC (reaktansi kapasitif) XLPE $240 \mathrm{~mm}^{2}$

$$
\begin{aligned}
\mathrm{XC} & =\frac{1}{\left(2 \times \pi \times 50 \times C e \times \text { total panjang saluran } \times 10^{-6}\right)} \\
& =\frac{1}{\left(2 \times \pi \times 50 \times 0,263 \times 478 \times 10^{-6}\right)} \\
& =25,3 \Omega
\end{aligned}
$$

XC (reaktansi kapasitif) total $=130,7+19,9+15,3$

$$
=175,9 \Omega
$$

Maka arus kapasitif suwung didapat,

$$
\begin{aligned}
\mathrm{I}_{\mathrm{ce}} & =\left(\frac{3 \times \text { Vsekunder } \times 1000 / \sqrt{3}}{X C \text { total penghantar }}\right) \\
\mathrm{I}_{\mathrm{ce}} & =\left(\frac{3 \times 20 \times 1000 / \sqrt{3}}{175,9}\right) \\
\mathrm{I}_{\mathrm{ce}} & =196,9 \mathrm{~A}
\end{aligned}
$$

\section{F. Setting Rele di Sisi Incoming $20 \mathrm{KV}$}

1. Setting Rele Gangguan Tanah

Rele gangguan tanah yang berada pada sisi incoming, waktu kerjanya diambil dengan ketentuan lebih lama 0,4 detik, sehingga waktu yang kerja rele gangguan tanah yang diinginkan selama $(0,3+0,4)$ detik $=0,7$ detik. Dengan menggunakan persamaan 1 dan 2 didapatkan nilai Iset dan nilai TMS pada sisi incoming $20 \mathrm{kV}$.

Iset $=0,1 \times$ gangguan tanah terkecil

$$
\begin{aligned}
& =0,1 \times 257,2 \\
& =25,72 \mathrm{~A} \\
\operatorname{tms} & =\frac{t \operatorname{set}\left(\left(\frac{\text { Ifault }}{\text { Iset }}\right)^{0,02}-1\right)}{0,14} \mathrm{SI} \\
& =\frac{0,7\left(\left(\frac{283,3}{25,72}\right)^{0,02}-1\right)}{0,14} \mathrm{SI} \\
& =0,25 \mathrm{SI}
\end{aligned}
$$

2. Pemeriksaan Waktu Kerja Rele Incoming

Waktu kerja relay incoming akan diperiksa dengan menggunakan nilai TMS yang sudah didapat dengan p-ISSN:1693 - 2951; e-ISSN: 2503-2372 
persamaan 2. Sesuai dengan persamaan 4 didapat waktu kerja relay incoming sebagai berikut.

a. Lokasi gangguan $25 \%$ panjang saluran

$$
\begin{aligned}
\mathrm{t} & =\frac{0,14 \times \mathrm{Tms}}{\left(\frac{\text { Ifault }}{\text { Iset }}\right)^{0,02}-1} \\
& =\frac{0,14 \times 0,25}{\left(\frac{276,9}{25,72}\right)^{0,02}-1} \\
& =0,71 \text { detik }
\end{aligned}
$$

b. Lokasi gangguan $50 \%$ panjang saluran

$$
\begin{aligned}
\mathrm{t} & =\frac{0,14 \times \mathrm{Tms}}{\left(\frac{\text { Ifault }}{\text { Iset }}\right)^{0,02}-1} \\
& =\frac{0,14 \times 0,25}{\left(\frac{272,3}{25,72}\right)^{0,02}-1} \\
& =0,72 \text { detik }
\end{aligned}
$$

c. Lokasi gangguan $75 \%$ panjang saluran

$$
\begin{aligned}
\mathrm{t} & =\frac{0,14 \times \text { Tms }}{\left(\frac{\text { Ifault }}{\text { Iset }}\right)^{0,02}-1} \\
& =\frac{0,14 \times 0,25}{\left(\frac{263,7}{25,72}\right)^{0,02}-1} \\
& =0,73 \text { detik }
\end{aligned}
$$

d. Lokasi gangguan $100 \%$ panjang saluran

$$
\begin{aligned}
\mathrm{t} & =\frac{0,14 \times \mathrm{Tms}}{\left(\frac{\text { Ifault }}{\text { Iset }}\right)^{0,02}-1} \\
& =\frac{0,14 \times 0,25}{\left(\frac{257,3}{25,72}\right)^{0,02}-1} \\
& =0,74 \text { detik }
\end{aligned}
$$

\section{G. Setting Rele di Sisi Penyulang Bunisari}

\section{Setting Rele Gangguan Tanah}

Sesuai dengan persamaan 1 didapatkan nilai pada sisi penyulang Bunisari:

$$
\text { Iset } \quad \begin{aligned}
& =0,1 \times \text { gangguan } 100 \% \text { penyulang } \\
& =0,1 \times 257,2 \\
& =25,72 \mathrm{~A}
\end{aligned}
$$

CT Ratio $=400: 5$

Arus gangguan yang dipilih untuk menentukan besarnya setting TMS relay GFR sisi penyulang $20 \mathrm{kV}$ yaitu arus gangguan hubung singkat satu fasa di $0 \%$ panjang penyulang. Waktu kerja paling hilir yang ditetapkan $\mathrm{t}=0,3$ detik. Jadi sesuai dengan persamaan 2 didapat nilai TMS:

$$
\begin{aligned}
\mathrm{tms} & =\frac{t \operatorname{tset}\left(\left(\frac{\text { Ifault }}{\text { Iset }}\right)^{0,02}-1\right)}{0,14} \mathrm{SI} \\
& =\frac{0,3\left(\left(\frac{283,3}{25,72}\right)^{0,02}-1\right)}{0,14} \mathrm{SI} \\
& =0,11 \mathrm{SI}
\end{aligned}
$$

2. Pemeriksaan Waktu Kerja RelePenyulang Bunisari

Waktu kerja relay incoming akan diperiksa dengan menggunakan nilai TMS yang sudah didapat dengan persamaan 2. Sesuai dengan persamaan 4 didapat waktu kerja relay penyulang Bunisari sebagai berikut.

a. Lokasi gangguan $25 \%$ panjang saluran

$$
\begin{aligned}
\mathrm{t} & =\frac{0,14 \times \mathrm{Tms}}{\left(\frac{\text { Ifault }}{\text { Iset }}\right)^{0,02}-1} \\
& =\frac{0,14 \times 0,11}{\left(\frac{276,9}{25,72}\right)^{0,02}-1} \\
& =0,305 \text { detik }
\end{aligned}
$$

b. Lokasi gangguan $50 \%$ panjang saluran

$$
\mathrm{t}=\frac{0,14 \times \text { Tms }}{\left(\frac{\text { Ifault }}{\text { Iset }}\right)^{0,02}-1}
$$

ISSN 1693 - 2951; e-ISSN: 2503-2372

$$
=\frac{0,14 \times 0,11}{\left(\frac{272,3}{25,72}\right)^{0,02}-1}
$$$$
=0,318 \text { detik }
$$

c. Lokasi gangguan $75 \%$ panjang saluran

$$
\begin{aligned}
\mathrm{t} & =\frac{0,14 \times \text { Tms }}{\left(\frac{\text { Ifault }}{\text { Iset }}\right)^{0,02}-1} \\
& =\frac{0,14 \times 0,11}{\left(\frac{263,7}{25,72}\right)^{0,02}-1} \\
& =0,32 \text { detik }
\end{aligned}
$$

d. Lokasi gangguan $100 \%$ panjang saluran

$$
\begin{aligned}
\mathrm{t} & =\frac{0,14 \times \mathrm{Tms}}{\left(\frac{\text { Ifault }}{\text { Iset }}\right)^{0,02}-1} \\
& =\frac{0,14 \times 0,11}{\left(\frac{257,3}{25,72}\right)^{0,02}-1} \\
& =0,326 \text { detik }
\end{aligned}
$$

e. Gangguan akibat arus gangguan penyulang lain

Sesuai persamaan 6 yang digunakan dalam mencari waktu kerja rele akibat pertambahan arus kapasitif dari penyulang lain, waktu kerja rele pada penyulang Bunisari adalah sebagai berikut.

$$
\begin{aligned}
& \mathrm{t}=\frac{0,14 \times \text { Tms }}{\left(\frac{\text { Ice bunisari+Ice suwung }}{(\text { Iset })}\right)^{0,02}-1} \\
& \mathrm{t}=\frac{0,14 \times 0,11}{\left(\frac{183,9+196,9}{25,72}\right)^{0,02}-1} \\
& \mathrm{t}=0,278 \text { detik }
\end{aligned}
$$

\section{H. Setting rele di sisi penyulang Suwung}

\section{Setting Rele Gangguan Tanah}

Sesuai dengan persamaan 1 didapatkan nilai pada sisi penyulang Suwung:

$$
\begin{aligned}
\text { Iset(definite) } & =0,1 \times \text { Gangguan } 100 \% \text { penyulang } \\
& =0,1 \times 245,9 \\
& =24,59 \mathrm{~A} \\
\text { CT Ratio } & =400: 5
\end{aligned}
$$

Arus gangguan yang dipilih untuk menentukan besarnya setting TMS relay GFR sisi penyulang $20 \mathrm{kV}$ yaitu arus gangguan hubung singkat satu fasa di $0 \%$ panjang penyulang. Waktu kerja paling hilir yang ditetapkan $t=0,3$ detik. Jadi sesuai dengan persamaan 3 didapat nilai tms :

tms

$$
\begin{aligned}
& =\frac{\operatorname{tset}\left(\left(\frac{\sqrt{\text { Ifault }{ }^{2}+\text { Ice }^{2}}}{\text { Iset }}\right)^{0,02}-1\right)}{0,14} \mathrm{SI} \\
& =\frac{0,3\left(\left(\frac{\sqrt{283,3^{2}+183,9^{2}}}{27,28}\right)^{0,02}-1\right)}{0,14} \mathrm{SI} \\
& =0,115 \mathrm{SI}
\end{aligned}
$$

\section{Pemeriksaan Waktu Kerja RelePenyulang Suwung}

Waktu kerja relay incoming akan diperiksa dengan menggunakan nilai tms yang sudah didapat dengan persamaan 2.3. Sesuai dengan persamaan 2.5 didapat waktu kerja relay penyulang Bunisari sebagai berikut.

a. Lokasi gangguan $25 \%$ panjang saluran

$$
\begin{aligned}
& \mathrm{t}=\frac{0,14 \times \text { Tms }}{\left(\frac{\sqrt{\text { Ifault }^{2}+\text { Ice bunisari }}}{\text { Iset }}\right)^{0,02}-1} \\
& \mathrm{t}=\frac{0,14 \times 0,115}{\left(\frac{\sqrt{260,4^{2}+183,9^{2}}}{24,59}\right)^{0,02}-1} \\
& \mathrm{t}=0,306 \text { detik }
\end{aligned}
$$

I Komang Anom Astana Ady: studi pengaruh setting rele 
b. Lokasi gangguan $50 \%$ panjang saluran

$$
\begin{aligned}
& \mathrm{t}=\frac{0,14 \times \text { Tms }}{\left(\frac{\sqrt{\text { Ifault }^{2}+\text { Ice bunisari }}}{\text { Iset }}\right)^{0,02}-1} \\
& \mathrm{t}=\frac{0,14 \times 0,115}{\left(\frac{\sqrt{255,4^{2}+183,9^{2}}}{24,59}\right)^{0,02}-1} \\
& \mathrm{t}=0,307 \text { detik }
\end{aligned}
$$

c. Lokasi gangguan $75 \%$ panjang saluran

$$
\begin{aligned}
& \mathrm{t}=\frac{0,14 \times \text { Tms }}{\left(\frac{\sqrt{\text { Ifault }^{2}+\text { Ice bunisari }}}{\text { Iset }}\right)^{0,02}-1} \\
& \mathrm{t}=\frac{0,14 \times 0,115}{\left(\frac{\sqrt{250,6^{2}+183,9^{2}}}{24,59}\right)^{0,02}-1} \\
& \mathrm{t}=0,309 \text { detik }
\end{aligned}
$$

d. Lokasi gangguan $100 \%$ panjang saluran

$$
\begin{aligned}
& \mathrm{t}=\frac{0,14 \times \text { Tms }}{\left(\frac{\sqrt{\text { Ifault }^{2}+\text { Ice bunisari }}}{\text { Iset }}\right)^{0,02}-1} \\
& \mathrm{t}=\frac{0,14 \times 0,115}{\left(\frac{\sqrt{245,9^{2}+183,9^{2}}}{24,59}\right)^{0,02}-1} \\
& \mathrm{t}=0,31 \text { detik }
\end{aligned}
$$

\begin{tabular}{|c|c|c|c|c|c|}
\hline \multirow{4}{*}{$\begin{array}{c}\text { Lokasi } \\
\text { gangguan } \\
\text { pada panjang } \\
\text { penyulang }\end{array}$} & $\begin{array}{c}\text { Rele } \\
\text { Incoming }\end{array}$ & \multicolumn{2}{|c|}{$\begin{array}{c}\text { Rele Penyulang } \\
\text { Bunisari }\end{array}$} & \multicolumn{2}{|c|}{$\begin{array}{l}\text { Rele Penyulang } \\
\text { Suwung }\end{array}$} \\
\hline & $\begin{array}{l}\text { Tms }= \\
0,25 \mathrm{SI}\end{array}$ & \multicolumn{2}{|c|}{$\mathrm{Tms}=0,11 \mathrm{SI}$} & \multicolumn{2}{|c|}{$\mathrm{Tms}=0,115 \mathrm{SI}$} \\
\hline & $\begin{array}{c}\text { Iset }= \\
25,72 \mathrm{~A}\end{array}$ & \multicolumn{2}{|c|}{ Iset $=25,72 \mathrm{~A}$} & \multicolumn{2}{|c|}{ Iset $=24,59 \mathrm{~A}$} \\
\hline & $\begin{array}{l}1 \text { Fasa } \\
\text { Tanah }\end{array}$ & $\begin{array}{l}1 \text { Fasa } \\
\text { Tanah }\end{array}$ & $\begin{array}{c}\text { Arus } \\
\text { penyu } \\
\text { lang } \\
\text { lain }\end{array}$ & $\begin{array}{l}1 \text { Fasa } \\
\text { Tanah }\end{array}$ & $\begin{array}{c}\text { Arus } \\
\text { penyula } \\
\text { ng lain }\end{array}$ \\
\hline $25 \%$ peny. & $\begin{array}{c}0,701 \\
\text { detik }\end{array}$ & $\begin{array}{l}0,305 \\
\text { detik }\end{array}$ & \multirow[t]{4}{*}{$\begin{array}{c}0,278 \\
\text { detik }\end{array}$} & $\begin{array}{c}0,306 \\
\text { detik }\end{array}$ & \multirow[t]{4}{*}{$\begin{array}{l}0,286 \\
\text { detik }\end{array}$} \\
\hline $50 \%$ peny. & $\begin{array}{l}0,702 \\
\text { detik }\end{array}$ & $\begin{array}{l}0,318 \\
\text { detik }\end{array}$ & & $\begin{array}{l}0,307 \\
\text { detik }\end{array}$ & \\
\hline $75 \%$ peny. & $\begin{array}{l}0,703 \\
\text { detik }\end{array}$ & $\begin{array}{l}0,32 \\
\text { detik }\end{array}$ & & $\begin{array}{l}0,309 \\
\text { detik }\end{array}$ & \\
\hline $100 \%$ peny. & $\begin{array}{l}0,704 \\
\text { detik }\end{array}$ & $\begin{array}{l}0,326 \\
\text { detik }\end{array}$ & & 0,31 detik & \\
\hline
\end{tabular}

e. Gangguan akibat arus gangguan penyulang lain

Sesuai persamaan 2.6 yang digunakan dalam mencari waktu kerja rele akibat pertambahan arus kapasitif dari penyulang lain, waktu kerja rele pada penyulang Bunisari dadalah sebagai berikut.

$$
\begin{aligned}
\mathrm{t} & =\frac{0,14 \times \text { Tms }}{\left(\frac{\text { Ice bunisari }+ \text { Ice suwung }}{(\text { Iset })}\right)^{0,02}-1} \\
\mathrm{t} & =\frac{0,14 \times 0,115}{\left(\frac{183,9+196,9}{24,59}\right)^{0,02}-1} \\
\mathrm{t} & =0,286 \text { detik }
\end{aligned}
$$

Tabel 3 : Hasil Setting Rele Gfr

\section{KESIMPULAN}

Berdasarkan perhitungan pada bagian sebelumnya, maka didapat beberapa kesimpulan yaitu sebagai berikut:

1. Dari hasil perhitungan dapat dilihat bahwa besarnya arus gangguan hubung singkat di pengaruhi oleh jarak titik

I Komang Anom Astana Ady: studi pengaruh setting rele gangguan, semakin jauh jarak titik gangguan maka semakin kecil arus gangguan hubung singkatnya, begitu pula sebaliknya.

2. Dari hasil perhitungan didapat nilai setting untuk Ground Fault Relay untuk menghilangkan Sympathetic Trip pada penyulang Bunisari - Suwung adalah sebagai berikut.

A. Penyetelan GFR yang didapat dari hasil perhitungan adalah

a. GFR di sisi incoming $20 \mathrm{kV}$ Iset $25,72 \mathrm{~A}$ tms $0,25 \mathrm{SI}$

b. GFR di sisi penyulang Bunisari Iset $25,72 \mathrm{~A}$ tms $0,11 \mathrm{SI}$

c. GFR di sisi penyulang Suwung Iset 24,59 tms $0,115 \mathrm{SI}$

\section{REFERENSI}

[1] A. Kadir, Distribusi Dan Utilisasi Tenaga Listrik. Jakarta, Indonesia: UI-Press, 2006.

[2] D. Marsudi, Operasi Sistem Tenaga Listrik.Yogyakarta, Indonesia: Graha Ilmu, 2006

[3] A. B. Cakasana, S. W. Rony dan P. Ontoseno, "Analisis Sympathetic Trip pada Penyulang Unggasan dan Bali Resort," Jurnal Teknik ITS, vol. 1, no. 1, 2012

[4] I. Affandi, "Analisa Setting Relai Arus Lebih Dan Relai Gangguan Tanah Pada Penyulang Sadewa Di GI Cawang," Skripsi, Universitas Indonesia, Jakarta, Indonesia, 2009

[5] B. Pandjaitan, Teknologi Sistem Pengendalian Tenaga Listrik Berbasis Scada. Jakarta, Indonesia: Prenhanlindo, 1999 
[Halaman ini sengaja dikosongkan] 